\title{
BADANIA EKSPERYMENTALNE WZMACNIANIA BARDZO KRÓTKICH WSPORNIKÓW ŻELBETOWYCH
}

\begin{abstract}
W referacie przedstawiono badania doświadczalne dotyczące wzmacniania istniejących krótkich wsporników za pomocą zbrojenia wklejanego. Proporcje wsporników modeli tej serii badawczej charakteryzował stosunek wysięgu do wysokości równy 1:3. Wyniki badań wykazały, że wzmacnianie zbrojeniem wklejanym może okazać się mniej efektywne niż w przypadku wsporników o większym wysięgu. W przypadku wsporników bardzo krótkich o nośności decyduje wytrzymałość betonu. Celem dodatkowego zbrojenia jest przekazanie sił rozciągających, działających poprzecznie do osi ukośnego krzyżulca ściskanego.
\end{abstract}

Słowa kluczowe: krótki wspornik, wytrzymałość betonu, zbrojenie wklejane, wzmacnianie, krzyżulec ściskany

\section{Wprowadzenie}

W referacie krynickim [1] autorzy przedstawili wyniki badań wsporników o proporcjach wysięgu do wysokości $a_{d} / h \approx 0,5$ i 0,6 wzmacnianych zbrojeniem wklejanym. Uzyskane wyniki potwierdziły znaczną skuteczność tego sposobu wzmacniania. Analiza wyników eksperymentalnych wykazała, że nośność po wzmocnieniu można określić za pomocą metody S-T, uzyskując bardzo dobrą zbieżność wyników doświadczalnych z teoretycznymi. Przy wspomnianych proporcjach wspornika i stosunkowo niskim stopniu zbrojenia głównego wynoszącym około $0,4 \%$, o nośności decydowało zbrojenie. Zniszczenie poprzedzone było uplastycznieniem zbrojenia głównego, a w niektórych przypadkach nawet jego zerwaniem. Badania przedstawione w referacie dotyczą wsporników krępych o stosunku wysięgu do wysokości $a_{d} / h \approx 0,3 \mathrm{~W}$ takim przypadku tangens

\footnotetext{
${ }^{1}$ Tadeusz Urban, Politechnika Łódzka

2 Autor do korespondencji/corresponding author: Łukasz Krawczyk, Katedra Budownictwa Betonowego, al. Politechniki 6, 90-924 Łódź, lukasz.krawczyk@p.lodz.pl

${ }^{3}$ Michał Gołdyn, Politechnika Łódzka
} 
kąta nachylenia krzyżulca ściskanego $\theta$ równy jest ok. 2,4, więc można stosować metodę Strut-and-Tie, która zgodnie z PN-EN 1992-1-1 [2] jest ograniczona warunkiem: $1,0 \leq \tan \theta \leq 2,5$. Badane wsporniki były blisko wartości granicznej, powyżej której można sprawdzać nośność wsporników według normy amerykańskiej ACI 318-14 [3] metodą shear - friction (ścinanie - tarcie). Celem tej serii badań było sprawdzenie skuteczności wzmacniania wsporników krótkich za pomocą zbrojenia wklejanego.

\section{Opis badanych elementów}

Na rysunkach 1 i 2 pokazano wymiary i zbrojenie badanych elementów. Jeden z nich o symbolu D-0 stanowił element odniesienia i nie podlegał wzmocnieniu. Pozostałe D-I, D-II i D-III zostały wzmocnione za pomocą wklejanych prętów gwintowanych M16 kl. $8.8 \mathrm{w}$ uprzednio wywiercone otwory. W przypadku modelu D-III stosowano również akcesorium stalowe oraz śruby M20 - patrz rys. 2.

Wszystkie badane modele były wykonane $\mathrm{z}$ tej samej mieszanki betonowej o maksymalnym ziarnie kruszywa $d_{g}=8 \mathrm{~mm}$. Pierwszy model D-0 badano po upływie $62 \mathrm{dni}$ od zabetonowania, natomiast ostatni - D-III, po 83 dniach. W dniu badania każdego modelu wykonywano towarzyszące badania wytrzymałości betonu na próbkach walcowych. Ze względu na bardzo małe różnice w wytrzymałości do analizy przyjęto średnią wytrzymałość dla całej serii $-f_{c m}=45,1 \mathrm{MPa}$. Ustalono również średni moduł sprężystości wynoszący $E_{c m}=27,2 \mathrm{GPa}$.

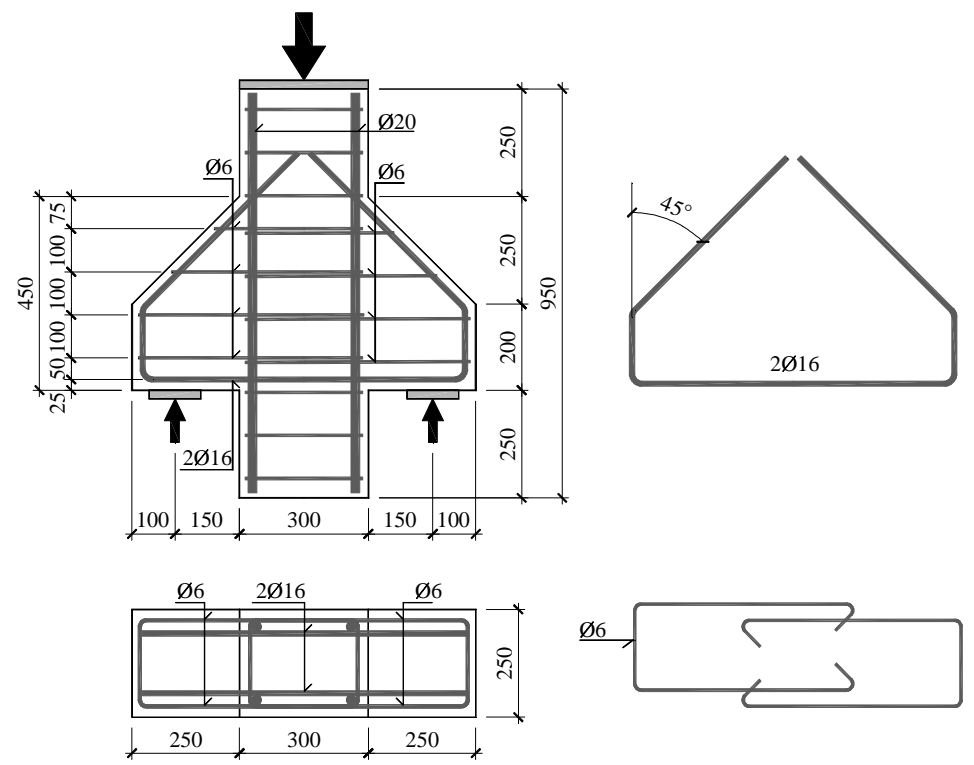

Rys. 1. Kształt, wymiary i zbrojenie badanych elementów przed wzmocnieniem

Fig. 1. Geometry and reinforcement of tested specimens before strengthening 


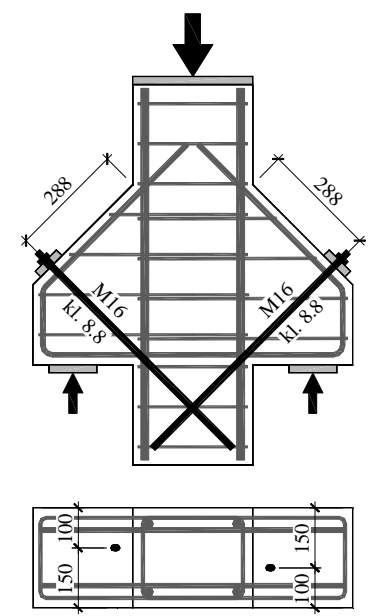

D-I
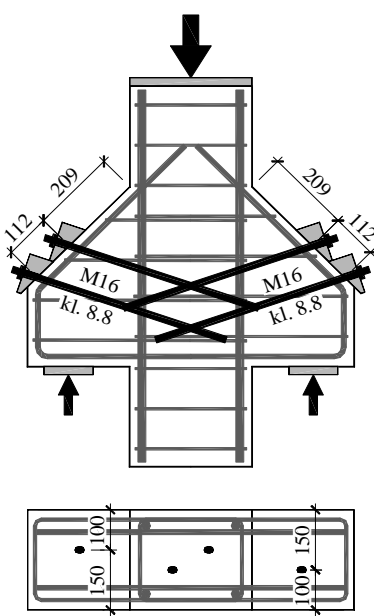

D-II
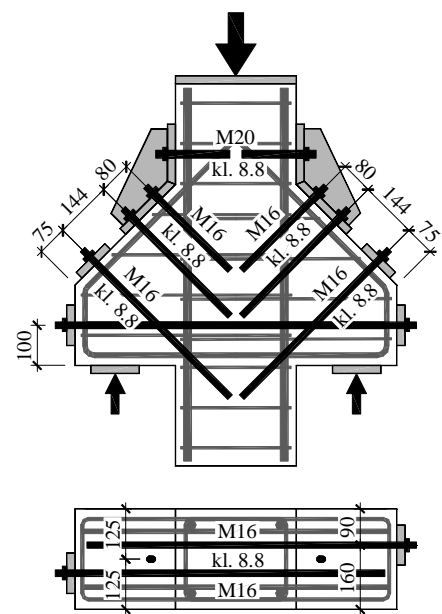

D-III

Rys. 2. Sposoby wzmocnienia elementów

Fig. 2. The methods of strengthening tested specimens

Parametry wytrzymałościowe zbrojenia określone na podstawie badań są następujące:

- zbrojenie główne $\mathrm{z}$ prętów $\varnothing 16, A_{s}=200,5 \mathrm{~mm}^{2}, f_{y m}=533,6 \mathrm{MPa}$, $f_{t m}=638,5 \mathrm{MPa}$;

- strzemiona (pręty gładkie) $\varnothing 6, A_{s}=28,1 \mathrm{~mm}^{2}, \quad f_{y m}=385,6 \mathrm{MPa}$, $f_{t m}=487,6 \mathrm{MPa}$;

- zbrojenie słupa $\varnothing 20, A_{s}=310,7 \mathrm{~mm}^{2}, f_{y m}=541,0 \mathrm{MPa}, f_{t m}=640,4 \mathrm{MPa}$.

\section{Realizacja badań}

Badania zostały przeprowadzone w maszynie wytrzymałościowej ZD600, pokazanej na rys. 3. Model oparty był na dwóch liniowych podporach przegubowych. Obciążenie przekazywano na słup za pomocą tłoka prasy. Badanie modeli wzmacnianych realizowano $w$ dwóch etapach. W pierwszym $\mathrm{z}$ nich prowadzono cykliczne, kilkukrotne obciążanie do $800 \mathrm{kN}$ i stopniowe odciążanie do $100 \mathrm{kN}$. Siła $800 \mathrm{kN}$ odpowiadała w przybliżeniu nośności obliczeniowej wsporników, co potwierdziło badanie modelu D-0. Stanowiła ona bowiem około $40 \%$ jego nośności eksperymentalnej, wynoszącej $1980 \mathrm{kN}$. Po zakończeniu trzech cykli obciążanie - odciążanie przystępowano do wzmacniania wsporników. Przy tym poziomie obciążenia wsporniki były już dość wyraźnie zarysowane (patrz rys. 4 ). 


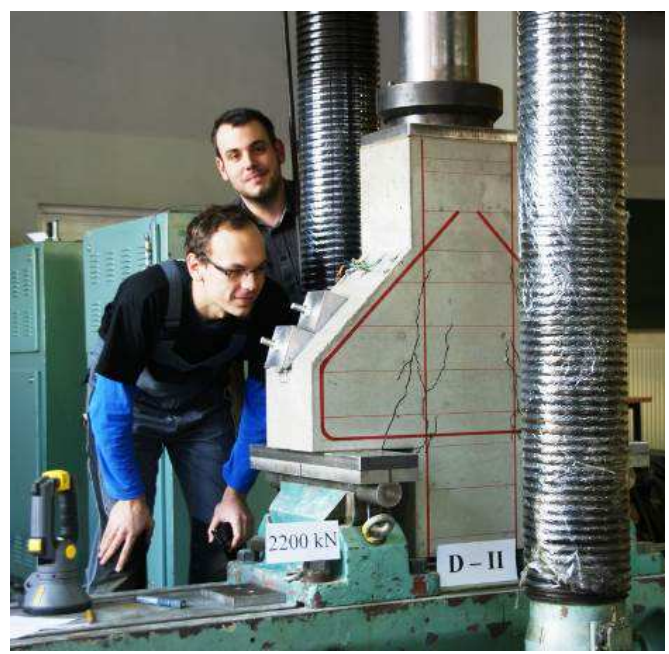

Rys. 3. Widok modelu D - II w stanowisku badawczym

Fig. 3. The corbel D - II in test setup

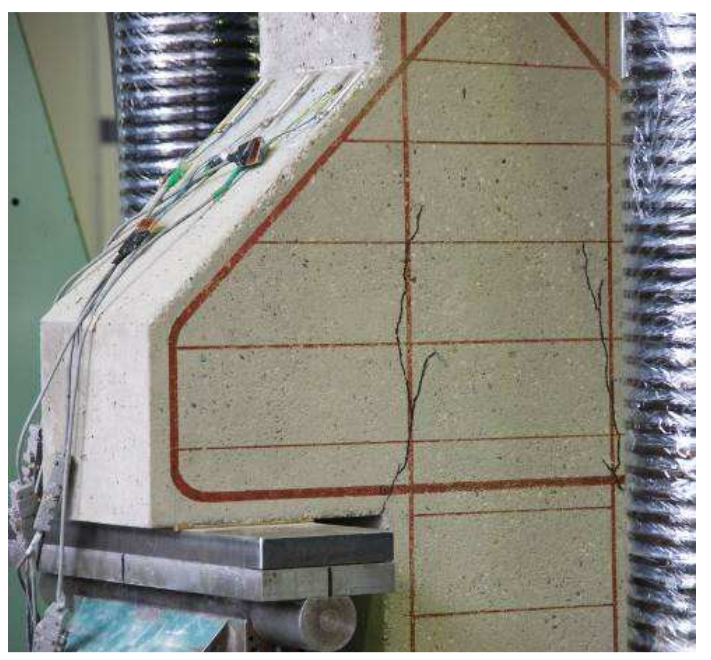

Rys. 4. Widok modelu D - 0 pod obciążeniem $800 \mathrm{kN}$ po trzech cyklach obciążenie-odciążenie Fig. 4. The corbel $\mathrm{D}-0,800 \mathrm{kN}$ load is applied

Wzmacnianie polegało na wywierceniu otworów, oczyszczeniu ich sprężonym powietrzem i szczotką $w$ celu usunięcia pyłu, wypełnieniu ich klejem i osadzeniu prętów wzmocnienia. Na rysunku 5 pokazano wybrane etapy wzmacniania modelu D-II, a na rys. 6 widok wsporników po wzmocnieniu. 

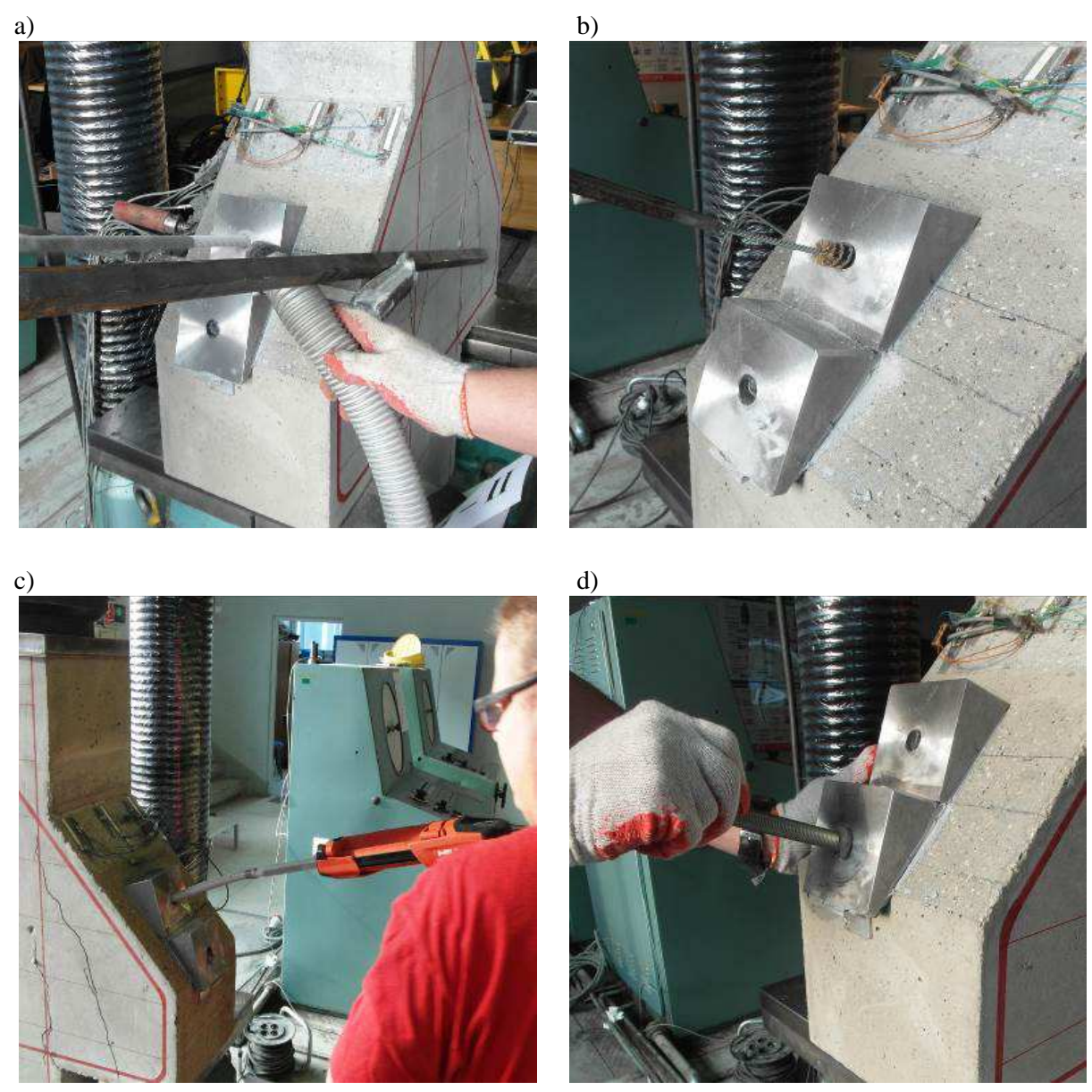

Rys. 5. Wzmacnianie modelu D-II: a) wiercenie otworu poprzez blok kotwiący, b) czyszczenie otworu, c) aplikacja kleju, d) osadzanie dodatkowego zbrojenia

Fig. 5. Strengthening of specimen D-II a) drilling the hole throught anchoring plate, b) clearing the hole, c) application of injectable mortar, d) embedding the additional reinforcement

Po osiągnięciu przez klej pełnej wytrzymałości, co następowało po około 2 godzinach od momentu osadzenia śrub, przystępowano do drugiego etapu obciążania modeli. Obciążenie zwiększano skokowo, co $100 \mathrm{kN}$ aż do zniszczenia. Widok zniszczonych modeli pokazano na rys. 7. 

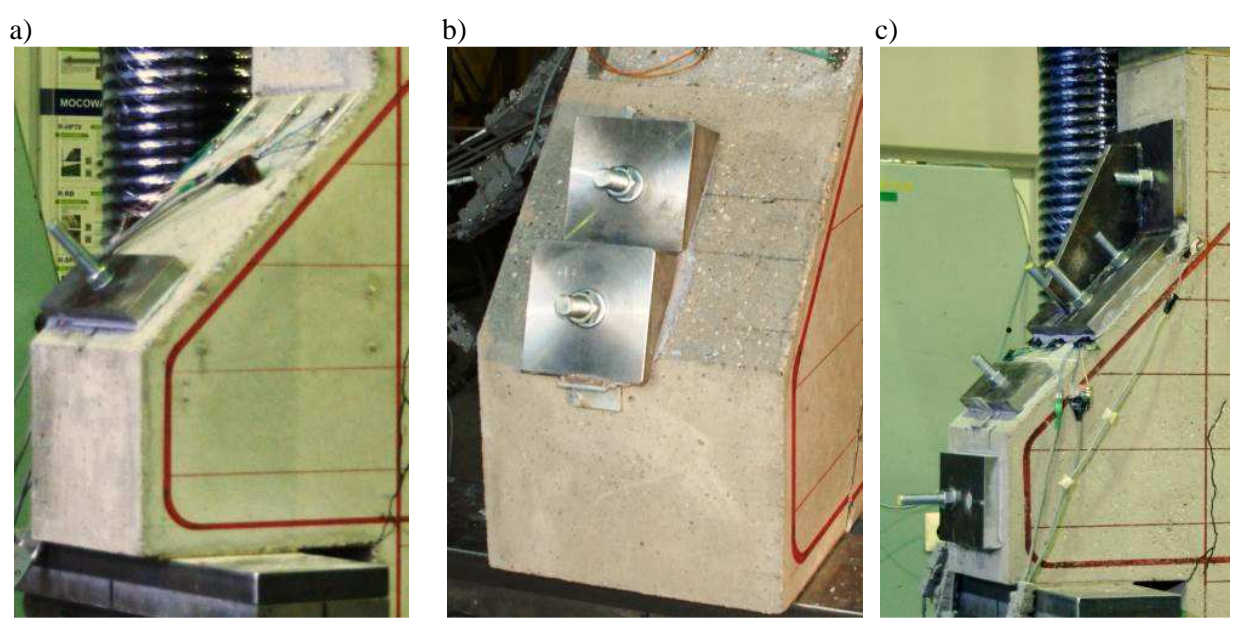

Rys. 6. Wsporniki po wzmocnieniu: a) D-I, b) D-II, c) D-III

Fig. 6. Corbels after strengthening a) D-I, b) D-II, c) D-III

\section{Wyniki pomiarów odkształceń}

W trakcie badań dokonywano pomiaru odkształceń betonu i zbrojenia pierwotnego - głównego i strzemion. Niestety część tensometrów uległa uszkodzeniu w trakcie cyklicznego odciążania i obciążania, dlatego też niemożliwe było przedstawienie wszystkich rezultatów. Na rysunku 8 pokazano wyniki pomiarów odkształceń na betonie, prowadzonych za pomocą tensometrów o bazie pomiarowej $10 \mathrm{~mm}$, usytuowanych na powierzchni ściskanej wspornika przy styku ze słupem. Zastosowanie prętów wklejanych jako wzmocnienia modeli D-I i D-II nie zmieniło w istotny sposób charakteru odkształceń względem modelu odniesienia. Inaczej było natomiast w przypadku elementu D-III, bowiem instalacja stalowego wzmocnienia znacznie ograniczyła tempo narastania odkształceń. Przy obciążeniu równym około $2000 \mathrm{kN}$ były one średnio dwukrotnie niższe $\mathrm{w}$ stosunku do pozostałych modeli. Ponadto $\mathrm{w}$ momencie zniszczenia odkształcenia betonu na powierzchni wspornika pod stalowych elementem usztywniającym dochodziły do $6 \div 7 \%$, znacznie przekraczając teoretyczne odkształcenia graniczne w stanie jednoosiowego ściskaniu $\varepsilon_{c u}=3,5 \%$. 

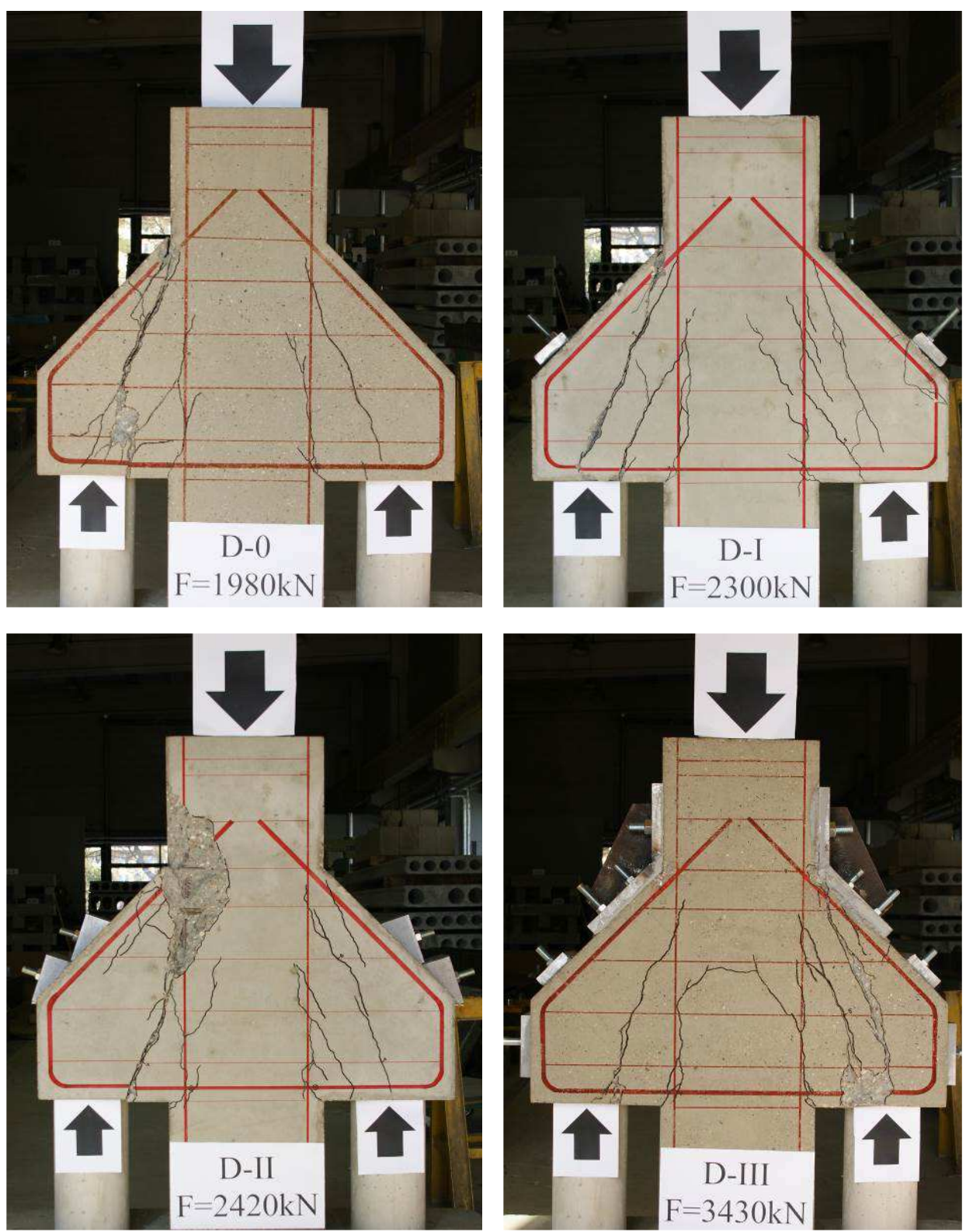

Rys. 7. Widok modeli po zniszczeniu

Fig. 7. Specimens after failure 
Na kolejnym rys. 9 pokazano odkształcenia zbrojenia głównego mierzone na styku krawędzi rozciąganej wspornika ze słupem. Widoczny jest wyraźny wpływ stalowego elementu wzmocnienia, współdziałającego razem ze zbrojeniem wklejanym. Zwiększeniu uległa sztywność wspornika D-III, skutkiem czego znacznie później, w stosunku do pozostałych elementów, doszło do uplastycznienia zbrojenia głównego. W przypadku modeli D-I i D-II nastąpiło to przy obciążeniu całkowitym równym około $1800 \div 1900 \mathrm{kN}$, wobec $2500 \mathrm{kN}$ w przypadku elementu D-III.
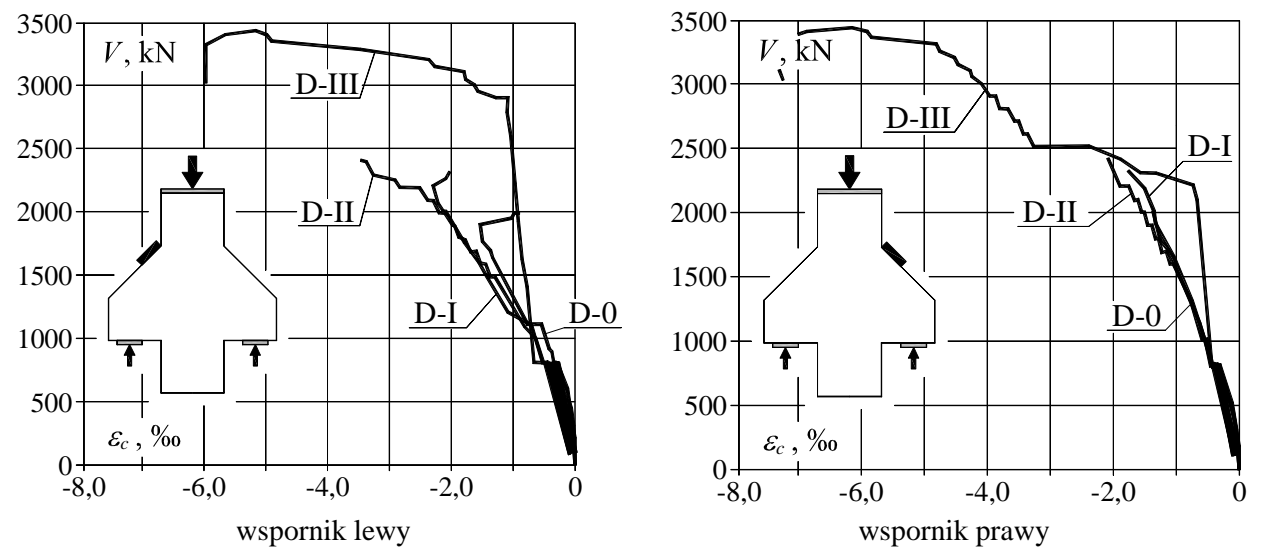

Rys. 8. Odkształcenia betonu

Fig. 8. Concrete strains

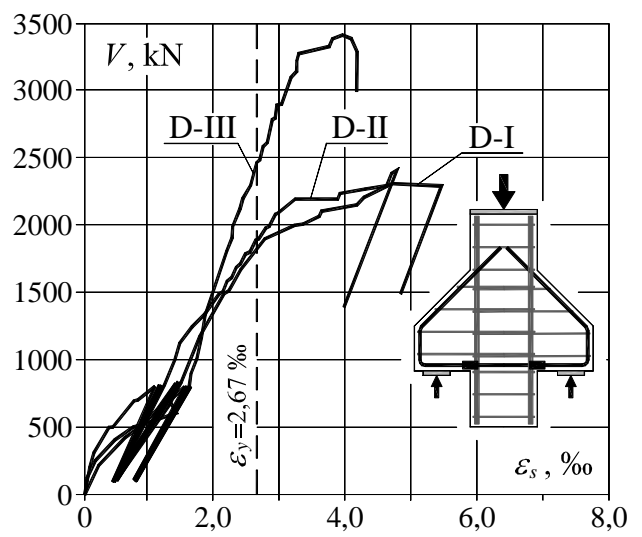

Rys. 9. Odkształcenia zbrojenia głównego

Fig. 9. Strains of main reinforcement 


\section{Zniszczenie modeli}

Zniszczenie modeli poprzedzone było uplastycznieniem zbrojenia głównego. W przypadku modeli D-0, D-I i D-II miało to miejsce przy sile równej około $1900 \mathrm{kN}$. Model D-0 uległ zniszczeniu w trakcie zwiększania nacisku tłoka w kolejnym kroku obciążenia. W przypadku modeli D-I i D-II uzyskano kilkunastoprocentowe zwiększenie obciążeń granicznych, równe odpowiednio 16 i $20 \%$. Obserwacja zarysowania modeli D-0 i D-I wskazywała, iż rysa o największej szerokości rozwijała się wzdłuż teoretycznego krzyżulca ściskanego, wynikającego z modelu kratownicowego. Można zatem przypuszczać, iż o ich nośności decydowała nośność krzyżulca ściskanego. $Z$ tego względu wzmocnienie modelu D-I za pomocą pręta ukośnego przecinającego krzyżulec tylko w jednym miejscu pozwoliło jedynie nieznacznie zwiększyć nośność wspornika.

Uwzględniając obserwacje poczynione w trakcie badania modelu D-I, zmodyfikowano koncepcję wzmocnienia elementu D-II. Wprowadzono dwa pręty prostopadłe do przebiegu teoretycznego krzyżulca ściskanego. Wymagało to zastosowana odpowiednich bloków kotwiących, widocznych na rys. 2 i 6 b. Zbrojenie to miało za zadanie „zszyć" rysę ukośną mniej więcej $\mathrm{w}$ połowie długości krzyżulca. Mimo dwukrotnego zwiększenia liczy prętów w stosunku do elementu D-I nie skutkowało to proporcjonalnym wzrostem nośności.

Niszczenie modelu zostało bowiem zapoczątkowane na styku nachylonej powierzchni wspornika i boku słupa patrz rys. 10. Z tego względu to newralgiczne miejsce zostało w modelu D-III wzmocnione stalowym okuciem, widocznym na rys. 6c. Zostało ono przyklejone do powierzchni elementu i dodatkowo zakotwione za pomocą wklejanych śrub. To rozwiązanie pozwoliło na znaczne podniesienie nośności o $73 \% \mathrm{w}$ stosunku do modelu odniesienia.

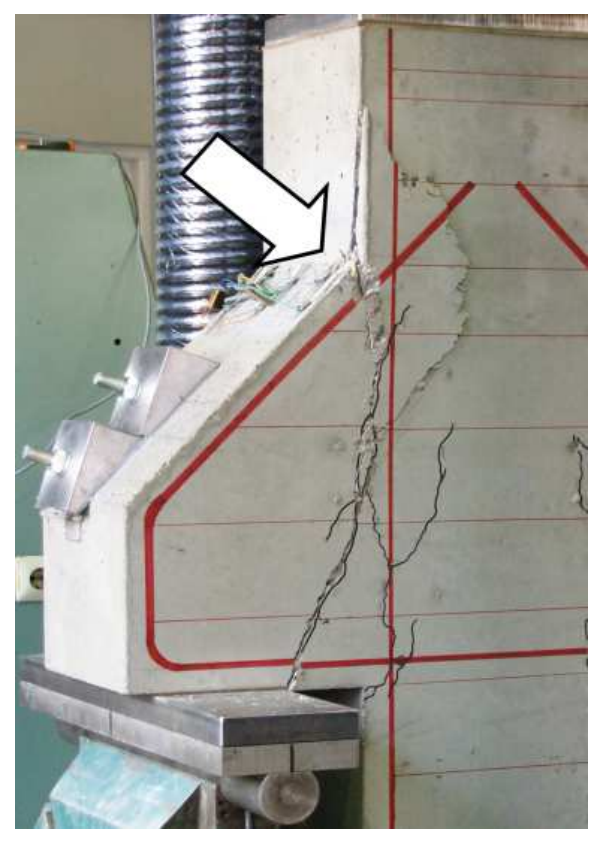

Rys. 10. Zniszczenie modelu D-II

Fig. 10. Failure of specimen D-II

\section{Wnioski}

Przeprowadzone badania wykazały, że wzmacnianie wsporników krępych o proporcjach $a_{c} / h<0,33$ za pomocą dodatkowego zbrojenia wklejanego może być mało efektywne. O ich nośności decyduje bowiem nośność krzyżulca ści- 
skanego. Wnioski te potwierdzają wyniki opublikowane przez NagrodzkaGodycka [4]. Zastosowanie prętów pełniących rolę zbrojenia poprzecznego „zszywającego" rysę pozwala jedynie nieznacznie zwiększyć nośność wspornika. W celu skutecznego ograniczenia zarysowania krzyżulca konieczne jest jednak zastosowanie znacznej ilości zbrojenia dodatkowego. $\mathrm{Z}$ tego względu bardziej efektywnym i latwiejszym $\mathrm{z}$ technicznego punktu widzenia działaniem wydaje się wzmacnianie betonu w miejscach przewidywanej destrukcji za pomocą stalowych okuć.

\section{Literatura}

[1] Urban T., Gołdyn M., Krawczyk Ł.: Wzmacnianie krótkich wsporników przez wklejanie dodatkowego zbrojenia. 61 Konferencja Naukowa KILiW PAN i KN PZITB Problemy naukowo-badawcze, Krynica 2015.

[2] PN-EN 1992-1-1 Eurokod 2 - Projektowanie konstrukcji z betonu - Część 1-1: Reguły ogólne i reguły dla budynków, Polski Komitet Normalizacyjny, Warszawa 2008.

[3] ACI 318-14 Building Code Requirements for Structural Concrete and Commentary for Building Code Requirements for Structural Concrete (ACI 318R-14), Farmington Hills, 2014.

[4] Nagrodzka-Godycka K., Wsporniki żelbetowe: badania, teoria, projektowanie, Wydawnictwo Politechniki Gdańskiej, 2001 s. 263.

\section{EXPERIMENTAL INVESTIGATIONS OF STRENGTHENING OF VERY SHORT REINFORCED CONCRETE CORBELS}

\section{S u m m a r y}

The paper presents experimental investigations concerning strengthening of very short corbels by post - installed bars. The slenderness of corbels $\left(a_{c} / h\right)$ was equal to $1 / 3$. The results showed that strengthening by the post - installed bars may be less effective than in the case of corbels with greater $a_{c} / h$ ratios. The carrying capacity of very short corbels is determined by concrete strength. The purpose of the additional reinforcement is transferring tensile forces acting laterally to concrete strut.

Keywords: short corbel, concrete strength, post - installed reinforcement, strengthening, strut

Przestano do redakcji: 07.06.2016 r.

Przyjęto do druku: 30.06.2016 r.

DOI: $10.7862 / r b .2016 .35$ 